\title{
EL PROCESO DE SEÑORIALIZACION DE LA TIERRA DE PLASENCIA (1252-1312)
}

\author{
Gloria Lora Serrano
}

Universidad de Sevilla

\section{RESUMEN:}

Este artículo estudia la señorialización que sufrieron las tierras del concejo de Plasencia desde la época de Alfonso X, momento en el que su alfoz padeció sus primeros recortes territoriales, hasta el reinado de Fernando IV, en el cual aquel proceso alcanzó una notable difusión debido a una serie de circunstancias tales como el fracaso de la labor repobladora del concejo de la villa o la necesidad que tuvieron los monarcas de retribuir a ciertos colaboradores, que en este caso concreto fueron en su mayor parte ciertos placentinos cabezas de los principales linajes de la villa.

PALABRAS CLAVE: Plasencia, Señoríos, Almaraz, Monroy, Belvís, Jaraicejo, Jarandilla, Valverde, Linajes, Trejo, Godínez

\section{RÉSUMÉ:}

Cet article étudie la seigneurial que souffrirent les terres du conseil municipal du Plasencia depuis l'époque du Alphonse X, au moment où son faubbourg connût ses premieres rognures territoriales, jusqu'à la fin du royaûme de Fernando IV, dans le quel ce processus ateint une notable difusion due à una serie de circonstances comme le fracas du travail de repeuplement du conseil de la villa ou la nessecité des monarques de rétribuer à certains colaborateurs concretament à une partie de certains placentinos tête des principaux lignage de la villa. 
MOTS CLEF: Plasencia, Seigneuries, Almaraz, Monroy, Belvís, Jaraicejo, Jarandilla, Valverde, Lignage, Trejo, Godínez

Extremadura fue una de las regiones del reino de Castilla en donde el régimen señorial adquirió unas dimensiones extraordinarias, hasta el punto de que al finalizar la Edad Media, la mayor parte del territorio estaba en manos de las órdenes militares o de la nobleza. No es de extrañar pues, que los trabajos de investigación sobre la nobleza extremeña y los señoríos que dominaban -su gran capital social en palabras de la profesora C. Quintanilla1_ hayan sido objeto del interés de los investigadores de la historia de aquella región desde fines del siglo pasado, época en la que A. Rodríguez Villa publicó su conocida y aún útil monografía sobre don Beltrán de la Cueva ${ }^{2}$. En las primeras décadas del siglo XX, ciertos estudiosos extremeños realizaron una serie de trabajos que si bien pueden adolecer de ciertos defectos de fondo y forma son, para los actuales investigadores del pasado medieval extremeño, de un extraordinario valor al incluir en los mismos las trascripciones de multitud de documentos que con el paso de los años se han perdido ${ }^{3}$.

Desde que en 1977 E. Cabrera Muñoz publicara El condado de Belalcázar (1444-1518). Aportación al estudio del régimen señorial en la Baja Edad Media 4 las investigaciones sobre señores y señoríos extremeños han experimentado una profunda renovación. La abundante bibliografía existente no sólo hace difícil una recopilación sino también puede hacerme caer en olvidos imperdonables. No obstante se hace preciso recordar los trabajos y monografías de F. Mazo, M.C. Gerbet, J.L del Pino y sobre todo A.

1 C. QUINTANILLA RASO: "El protagonismo nobiliario en la Castilla Bajomedieval". Medievalismo. Boletín de la Sociedad Española de Estudios Medievales, 7 (1997), p. 204.

2 Bosquejo bibliográfíco de D. Beltrán de la Cueva, primer duque de Alburquerque. Madrid, 1881.

3 No se puede olvidar la obra en este sentido de V. PAREDES GUILLÉN: Los Zúñigas, señores de Plasencia, Cáceres, 1909. "El señorío de Las Garrovillas", B.A.H., T. XXXIX. "El señorío de Monroy". Rev. de Extremadura, 1905. Muy útiles los trabajos de M. MUÑOZ DE SAN PEDRO: Puntualizaciones Históricas sobre el linaje de los Monroy, Badajoz, 1965. La Extremadura del siglo XV en tres de sus paladines, Madrid, 1964. Don Gutierre de Sotomayor, maestre de Alcántara. Cáceres, 1949.

4 Publicado en Córdoba, 1977. 
Franco ${ }^{5}$. Pero aún queda un largo camino por recorrer porque la mayor parte de estas obras están centradas en el siglo XV con lo cual, los linajes de los siglos XIII y XIV así como los señoríos sobre los que ejercieron su poder están en la oscuridad, especialmente los de la primera centuria. Esta situación se hace preciso remediar puesto que en algunos casos los componentes de aquellas familias fueron los antecesores de los grandes linajes y señoríos extremeños de fines de la Edad Media. Por otra parte, falta por realizar el estudio de los linajes de la nobleza local ya que aunque estas familias no tuvieron el potencial económico y político de los grandes casas señoriales, Estúñigas, Alvarez de Toledo, Pachecos, Luna, Suárez de Figueroa- sí que poseyeron notable importancia a nivel regional al vivir en sus señoríos y al estar implicados profundamente en la vida de la región.

Este trabajo pretende ser una aportación al conocimiento del proceso de señorialización que las tierras del término de Plasencia experimentaron durante los reinados de Alfonso X, Sancho IV y Fernando IV, así como de algunos linajes placentinos cuyos orígenes son oscuros e incluso en algunas ocasiones están envueltos en leyendas. Es pues una pequeña contribución al mejor conocimiento del mapa señorial de la Alta Extremadura.

5 F. MAZO ROMERO: El condado de Feria (1394-1505). Contribución al estudio del proceso señorializador de Extremadura durante la Edad Media. Badajoz, 1980. M.C. GERBET: La noblesse dans les royaumes de Castille. Etude sur ses structures sociales en Extrémadure de 1454 a 1516. Paris, 1979. J.L. del PINO GARCÍA: Extremadura en las luchas políticas del siglo XV. Badajoz, 1991. A. FRANCO SILVA: "La hacienda de un noble castellano a comienzos del siglo XV. El mariscal García González de Herrera”. En la España Medieval, V (1986), “Oropesa. El nacimiento de un señorío toledano a fines del siglo XIV”. A.E.M., 15 (1985). "Las rentas señoriales de las villas extremeñas de Alburquerque y la Codesera". H.I.D., 25 (1998). "El mariscal García de Herrera y el marino D. Pedro Niño, conde de Buelna. Ascenso y fin de dos linajes de la nobleza nueva de Castilla". H.I.D., 15 (1990). En colaboración con J.L. del PINO GARCÍA: "El Campo de Arañuelo en el siglo XV: Problemas y conflictos entre los señores de Oropesa y la ciudad de Plasencia". Estudios de Historia y Arqueología Medievales, IX (1993) y "El señorío de los Monroy (siglos XIIIXV)". Actas del Congreso Hernán Cortés y su tiempo. V Centenario (1485-1985), Mérida, 1987. En colaboración con J.A. GARCÍA LUJÁN: "Los Pacheco. La imagen mítica de un linaje portugués en tierras de Castilla". Actas das II Jornadas de Historia Medieval. Porto, 1989. 
I.-El término de Plasencia.

En una fecha imprecisa de la primera mitad de 1186 Alfonso VIII de Castilla fundó la ciudad de Plasencia a orillas del río Ambroz, en un territorio situado en la zona más meridional de sus dominios. La conquista cristiana de este espacio, acaecida a fines del siglo XII, hay que insertarla en el complicado panorama político del momento, cuando una serie de poderes castellano, leonés, portugués y almohade- pugnaban por el control de la región. El monarca castellano deseaba no sólo potenciar su presencia en esa zona y defender la frontera sur de su reino, amenazada por musulmanes leoneses y portugueses sino también potenciar su repoblación 6 . En efecto, aquel territorio pertenecía a la comunidad de Villa y Tierra de Ávila, la más extensa de las comunidades de villa y tierra de la Extremadura castellana, cuyo concejo tenía serias dificultades para atender las necesidades de defensa y repoblación de aquél territorio marginal ${ }^{7}$. Todas estas consideraciones llevaron al monarca castellano a erigir una nueva villa cabeza de una Comunidad de Villa y Tierra para lo cual en la primavera de 1186, desde Toledo, se dirigió a aquella zona y sobre un cerro rodeado por el río Jerte

6 La bibliografía en torno a la fundación de Plasencia es abundante. En los trabajos del profesor J. GONZÁLEZ: El reino de Castilla en época de Alfonso VIII, Escuela de Estudios Medievales, 3 Vols. Madrid, 1960. La repoblación de Castilla la Nueva, Madrid, 1960. Regesta de Fernando II, Madrid, 1943, Reinado y Diplomas de Fernando III, Publicaciones del Monte de Piedad y Caja de Ahorros de Córdoba, 1986, se encuentran muchas de las opiniones y documentos utilizados en este texto. Trabajos más recientes donde también se trata este asunto son los de E.C. SANTOS CANALEJO: La historia medieval de Plasencia y su entorno geo-histórico. La Sierra de Béjar y la Sierra de Gredos. Institución Cultural El Brocense, Cáceres 1986 y de B. PALACIOS MARTíN: "Fundación y organización de Plasencia". I Congreso de Estudios Históricos sobre Plasencia y su Tierra, Plasencia, 1987 (Inédito).

7 MARTÍNEZ DÍAZ, G.: Las comunidades de Villa y Tierra de la Extremadura Castellana, Ed. Nacional, Madrid, 1983, p. 634. MORENO NÚÑEZ, J.I.: "La creación de nuevas pueblas por Alfonso X: la repoblación tardía del Campo de Arañuelo". En la España Medieval, 15, (1992), p. 102. J. GONZÁLEZ: "La Extremadura castellana al mediar el siglo XIII”, Hispania, t. 127, pp. 416-424. J. GONZÁLEZ: La repoblación de Castilla... Vol. I, pp. 294-295. 
fundó Plasencia. Allí se encontraba el citado monarca el 12 de junio de 1186, in diebus fundationis eiusdem urbis ${ }^{8}$.

La fundación de Plasencia originó, desde un principio, importantes cambios en el territorio ya que significó la llegada de pobladores a un lugar hasta entonces prácticamente vacío de población, hecho de capital importancia para comprender mejor el posterior proceso señorializador que sufrieron las tierras de su término. Pero aquéllos cambios en la estructura de poblamiento y en el paisaje del territorio hubieron de ser muy lentos y en bastantes ocasiones nos consta que el proceso repoblador experimentó ciertos retrocesos debido entre otras razones a la débil demografía del reino castellano. Por otra parte, el estudio de dicho proceso repoblador es muy difícil de seguir, puesto que apenas si hay noticias que nos informen sobre los primeros años de la vida de Plasencia que indudablemente fue muy dura -dada su proximidad a la frontera con los musulmanes- por lo que bien podía considerarse a fines del siglo XII como una marca fronteriza. Y la peligrosidad de su situación se puso de manifiesto en 1196 cuando fue asaltada por los almohades en el curso de la expedición que ese año organizó el Miramamolín 9 . Tras el ataque, Alfonso VIII acudió a recuperar la ciudad, entrando en la misma por el lado Sur el 15 de agosto de 1196. Plasencia fue de nuevo repoblada $y$, para evitar un nuevo embate musulmán, se construyeron unas gruesas murallas ${ }^{10}$, dentro de las cuales se organizó la ciudad que desde su época más antigua contó al menos con cinco collaciones, según establecía el fuero que Alfonso VIII le concedió en fecha no determinada, pero que se puede situar entre 1186 y 1208; aquéllas fueron la de San Pedro, San Martín, San Vicente, San Esteban y San Nicolás. Extramuros se situaron los conventos de San Marcos, San Juan, Santa Cruz y San Roque y una serie de ermitas ${ }^{11}$. Dicho fuero y la serie de privilegios que

8 GONZÁLEZ, J.: El reino de Castilla..., pp. 942-943. Ibídem: La repoblación de Castilla la Nueva, 2 vols. Universidad Complutense. Madrid, 1975, p. 294.

9 Ibídem, p. 295.

10 Fray Alonso FERNÁNDEZ: Historia y Anales de la ciudad y obispado de Plasencia, Biblioteca Extremeña. Asociación Cultural Placentina Pedro de Trejo, S.F., S.L., p. 14.

11 Hay un cierto desacuerdo entre los historiadores en torno al año en el que Alfonso VIII otorgó el fuero a Plasencia. A. GARCÍA ULECIA piensa que fue concedido entre 1186 y 1196. Los factores de la diferenciación entre las personas en los fueros de la Extremadura castellano-leonesa. Universidad de Sevilla, 1975, p. 19. El profesor J. GONZÁLEZ, por su parte, declara que la fecha es más tardía, en concreto, 1208. El reino de Castilla en época..., 
los sucesores de Alfonso VIII otorgaron a Plasencia intentaron atraer pobladores al nuevo territorio puesto que uno y otros aseguraban a los potenciales vecinos amplias libertades y generosas franquicias que debían hacer más atractiva la vida en la población 12 .

En esta época se organizó la vida de la nueva ciudad y de su territorio bajo el amparo de la tregua acordada después de la batalla de Las Navas de Tolosa y la protección que le ofrecía la Orden Militar que señoreaba Monfragüe y Albalá. Pero es muy difícil saber cómo se articuló aquélla ya que como acabo de señalar la documentación generada tras la fundación definitiva de Plasencia es escasa: la municipal se ha perdido prácticamente en su totalidad y en el Archivo del Obispado los documentos que se refieren a los siglos XII y XIII escasean ${ }^{13}$. Por otra parte no existen para Extremadura Libros de Repartimiento que nos informen sobre la organización del territorio durante la etapa almohade. En definitiva, lo único que sabemos es que fue a comienzos del siglo XIII cuando se debió iniciar el proceso de organización territorial y de transformación del paisaje preexistente como consecuencia de la llegada de pobladores que pertenecían a una civilización diferente a la musulmana, con unos intereses sociales y económicos distintos, que quedaron reflejados en la organización espacial y en el paisaje.

p. 112. La edición del fuero que voy a utilizar es la de E. RAMÍREZ VAQUERO y M. T. VAQUERO RAMÍREZ: El Fuero de Plasencia, Junta de Extremadura, Mérida, 1990.

12 G. LORA SERRANO: "El primer gobierno municipal de Plasencia". H.I.D., (en prensa).

13 Desde hace unos años se vienen publicando o reeditando obras de ciertos eruditos extremeños cuyas páginas contienen multitud de trascripciones de documentos que en muchos casos se han perdido. El problema fundamental que nos podemos encontrar al utilizar este tipo de fuentes es que nos pueden llevar a falsas conclusiones ya que en ocasiones, especialmente frecuentes en la obra de D. Sánchez Loro, las trascripciones contienen una serie de errores. No obstante, en este trabajo he utilizado ampliamente la obra ingente y encomiable de estos extremeños al ser los documentos aportados en su trabajo los únicos de los que dispongo para el análisis de ciertos aspectos de este artículo. Fray Alonso FERNÁNDEZ: Historia y Anales de la ciudad y Obispado ... BENAVIDES CHECA, J. Prelados Placentinos. Notas para sus biografías y para la Historia documental de la Santa Iglesia Catedral y Ciudad de Plasencia, 1907. Ayuntamiento de Plasencia, Febrero, 2000. SÁNCHEZ LORO, D.: Historias Placentinas Inéditas. Catalogus Episcoporum Ecclesiae Placentinae. Primera Parte. Vol. A, B y C. Institución Cultural El Brocense. Cáceres, 1982 y El parecen de un deán. Cáceres, 1959. 
Los algo más de $4.800 \mathrm{~km}^{2}$ que tenía el término placentino fueron dividido en tres sexmerías. La más septentrional fue la del Valle y Trasierra. Sus tierras estaban recorridas por el río Jerte y esta fue la sexmería que más pronto se pobló. En ella estaba Plasencia y algunas villas de cierta consideración tales como las de Tornavacas, Navaconcejo, Jerte o Garganta la Olla. La sexmería de la Vera se ubicaba en el centro del término placentino; el Tiétar cruzaba este distrito rural que fue poblado entre finales del siglo XIII y comienzos del XIV. Las aldeas y lugares más notables fueron Jaraiz, Gargüera, Valverde de la Vera o Arroyomolinos. Por último estaba la sexmería del Campo de Arañuelo, un enorme territorio de $2.800 \mathrm{~km}^{2}$. que incluía las comarcas geográficas de Mirabel, Ibor y Almonte. Grimaldo, Monroy, Torrejón, Almaráz y Belvís fueron algunos de sus centros de población más notables. El estudio de los testimonios conservados y de la toponimia nos ofrece la imagen de un tremendo espacio prácticamente virgen, muy quebrado por montes y gargantas y cubierto por bosques de alcornocales, encinas y robles junto a matorrales entre los que se encontraban piornos, cañales, helechos y piñuelas ${ }^{14}$.

\section{II.-El proceso señorializador del término de Plasencia.}

A pesar de que el título 165 de su fuero declaraba que Plasencia y las villas y aldeas situadas en su término no tendrían otro señor que el rey, una serie de circunstancias provocaron que muy pronto el amplio término que acabamos de señalar empezara a ser recortado debido a un proceso de enajenación de tierras en favor de determinados personajes. Este fenómeno, que como he señalado al principio de este trabajo fue común a todas las tierras de Extremadura ${ }^{15}$, se vivió en Plasencia y su término, a partir del siglo XIII, con especial intensidad y está muy ligado a las dificultades que planteaba la repoblación del territorio. En un principio, aquélla estuvo dirigida por el

14 J. CLEMENTE RAMOS, J.L. DE LA MONTAÑA CONCHIÑA: "La Extremadura cristiana (1142-1230). Ocupación del espacio y transformaciones socioeconómicas", H.I.D., 21 (1994), pp. 104 y ss.

15 Sobre el proceso de señorialización de Extremadura, E. CABRERA, G. LORA: "Datos sobre la población y la configuración jurisdiccional de Extremadura en el tránsito de la Edad Media a la Moderna", IFIGEA, (I), Córdoba, 1984, pp. 62-75. 
concejo de la ciudad. No son muchos los datos que sobre este asunto poseemos pero sabemos que alrededor del año de 1218 el cabildo placentino estaba inmerso en la repoblación de sus términos situados al sur del Tajo, concretamente del castillo de Miravete, entre Albalá y Trujillo ${ }^{16}$, y poco después Fernando III concedió al concejo de Plasencia el castillo de la vecina Belvís cum suo termino ad populandum et laborandum ${ }^{17}$, con lo cual impulsaba la repoblación de ese territorio situado en la sexmería del Campo de Arañuelo. Por lo que respecta a la forma en la que la repoblación se desarrollaba conocemos, por un ordenamiento realizado por el cabildo placentino en 1285, que uno de los alcaldes daba tierras para labrar a los vecinos que tuvieran bueyes ${ }^{18}$.

El resultado de la tarea colonizadora no fue satisfactorio, debido a las dificultades con las que se enfrentaron los colonos. Algunas eran comunes en todo el reino, como la acusada debilidad demográfica de Castilla. A esta realidad habría que sumar el hecho de que el rápido avance militar del siglo XIII determinó que se concentraran todos los esfuerzos en repoblar los territorios conquistados, como una forma de consolidar a su vez la reciente ocupación militar. Y ello, en cierta forma, dificultaba la colonización de los despoblados territorios de la Meseta por la emigración de campesinos atraídos, sin duda, por los fértiles suelos del valle del Guadalquivir. Pero además, en el caso concreto del territorio que analizamos hay que considerar la inseguridad de algunas zonas, tanto por su carácter de frontera -no hay que olvidar la presencia de guarniciones musulmanas muy cerca puesto que Trujillo no fue conquistada hasta el mes de enero de 1233- como por la presencia de golfines. A esta negativa situación hay que unir la poca calidad de sus suelos a efectos agrícolas, sobre todo en el Campo de Arañuelo, la falta de un puente para atravesar el Tajo y los conflictos suscitados con la vecina Comunidad de Villa y tierra de Ávila ${ }^{19}$, que provocaron, sin lugar a dudas,

16 J. GONZÁLEZ: Reinado y diplomas de Fernando III..., Vol. I., p. 424.

17 Ibídem, Vol. II, dcto. 7. n.141, pp. 169-170.

18 J. BENAVIDES CHECA: Prelados Placentinos..., pp. 311-312.

19 La creación de la Comunidad de Villa y Tierra de Plasencia a costa de la Comunidad de Villa y Tierra de Avila planteó una serie de problemas entre ambas, ya que a Ávila no sólo le habían sido segregados parte de sus $15.000 \mathrm{Km}^{2}$ de su alfoz, sino que además se cortaba a las milicias abulenses el camino hacia las tierras musulmanas del Sur, donde los caballeros de Ávila efectuaban tradicionalmente correrías de la que obtenían botín y por las que ampliaban el territorio de la ciudad por el Sur. J. GONZÁLEZ: La Extremadura castellana al mediar el 
que hasta fines del siglo XIII la población apenas si creciese. Un documento de 1254 declara que sólo poseían iglesia once pueblos del término de Plasencia ${ }^{20}$, y además algunos lugares se despoblaron y no volvieron a habitarse: S. Pedro, Palacios, Ojalvo, el castillo de Miravete...fueron algunos de estos despoblados ${ }^{21}$.

Este fracaso unido a la necesidad de los monarcas de retribuir a sus colaboradores más cercanos llevó a aquéllos a realizar una política de enajenación de tierras del concejo a favor de dichos personajes que en el caso que nos ocupa eran bien funcionarios de la corte o bien miembros de la oligarquía de Plasencia. De esta forma no sólo premiaban ciertos servicios que aquéllos les prestaban, tanto en la villa como en el reino, sino que además daban un fuerte impulso a la repoblación en la que tan interesados estaban los monarcas.

\section{A.-Los primeros señoríos: El reinado de Alfonso X.}

Si seguimos ciertas noticias ofrecidas por Domingo Sánchez Loro el primer señorío surgido en el término de Plasencia fue el de Almaraz, creado en una fecha imprecisa por Fernando III en favor de su prima Beatriz Alfonso, hija del Infante don Juan. Este mismo autor añade, basándose en la transcripción de otro privilegio de Fernando III, que el monarca en 1225 concedió a su prima que pudieran ir a poblar a Almaraz 100 colonos, que quedarían exentos de todo pecho por espacio de veinte años, aunque sí tendrían que pagar la moneda forera y el portazgo en Burgos, Toledo, Sevilla y Murcia $^{22}$. Los documentos fernandinos no los he logrado encontrar y, o se han perdido o quizás no existieron pues ni el profesor Julio González los cita

siglo XIII..., pp. 373-378. En este contexto debemos situar el conflicto planteado en 1251 por ciertas edificaciones y poblaciones hechas por el concejo de Plasencia en territorio abulense. Reinado y diplomas de Fernando III..., Vol. III, dcto.. 833, p. 418.

20 V. PAREDES GUILLEN: Los Zúñigas, señores de Plasencia, Cáceres, 1909, p. 65, nota 1 infra.

21 Ibídem. Cuando en 1289 se deslinda la dehesa de Ferruz se cita en "castillejo caído de Miravete" ACPL, (Archivo Catedral de Plasencia) Leg.94-9b, fols. 12r.-13r.

22 El autor declara que lo ha tomado de un manuscrito de Ascensio de Morales. Historias Placentinas Inéditas...., pp. 275 y 364-365. Por su parte, otro erudito extremeño, J. BENAVIDES CHECA también hace referencia a este documento aunque lo fecha en 1220. Prelados Placentinos..., p. 310. El autor señala que dicho documento en el siglo XVIII se conservaba en el archivo municipal. 
en su magna obra sobre Fernando III, ni otros autores y genealogistas consultados identifican a ningún tío del rey don Fernando llamado don Juan ni a ninguna prima con el nombre de Beatriz Alfonso ${ }^{23}$. Por estas razones y porque ciertas noticias y documentos de fines del siglo XIII y comienzos del XIV ofrecen otra información, la creación en fecha tan temprana del señorío de Almaraz me ofrece serias dudas. No obstante no quiero dejar de consignarla al haber sido tenida por cierta por otros estudiosos ${ }^{24}$.

A mediados del siglo XIII la tierra placentina fue objeto de una serie de recortes territoriales: en mayo de 1265 Alfonso X concedió a Don Durán 10 yugadas de tierra en Almaraz. La carta de merced tampoco ha llegado a mi poder en su forma original pero se conoce por una copia inserta en un pleito de comienzos del siglo XIV. Aunque el monarca no concedió Don Durán ninguna jurisdicción sobre el territorio donado, éste fue el germen del futuro señorío de Almaraz que disfrutaron los sucesores de este caballero ${ }^{25}$. Alfonso $\mathrm{X}$ siguió concediendo tierras del alfoz de Plasencia a otros hombres de su confianza como Gonzalo Godínez, "escribano y notario público del rey en

23 En el cuadro genealógico expuesto en la p. 14 de la obra del profesor G. MARTÍNEZ DIEZ: Fernando III (1217-1252), Palencia, 1993 y titulado "Antepasados de Fernando III" no aparecen los personajes citados en el documento en cuestión, como tampoco están en el cuadro de los "Reyes de Castilla y León" publicado en la "Enciclopedia de Historia de España" dirigida por M. ARTOLA. Alianza Editorial, Madrid, 1988. El Infante don Juan, tío del rey Fernando IV que efectivamente recibió Almaraz, era el hijo de Alfonso X. Vid. "Cuadro genealógico de la familia de Alfonso X". M. GONZÁLEZ JIMÉNEZ: Alfonso X. (1252-1284). Palencia, 1993, p. 331. S. DE MOXO dice que "ese turbulento personaje" casó dos veces, pero de ninguno de sus matrimonios, tuvo a una hija llamada Beatriz. "De la nobleza vieja a la nobleza nueva. La transformación nobiliaria castellana en la Baja Edad Media". Cuadernos de Historia, 3, (1969), pp. 180-181. Por su parte L. de SALAZAR y CASTRO en su Historia genealógica de la Casa de Lara, T. II, fol. 589 ofrece un completísimo cuadro genealógico de este infante donde la citada tampoco Beatriz Alfonso aparece. Ed. Facsímil. Wilson Editorial, Acedo, Navarra, 1988. P. SALAZAR DE MENDOZA en su Origen de las dignidades seglares de Castilla y León dice que tuvo una hija llamada doña María de Haro, señora de las casas de Vizcaya y de la Lara. Lib. III, fol. 182. Ed. facsímil. Universidad de Granada, 1988.

24 E.C. DE SANTOS CANALEJO: La historia medieval de Plasencia y su entorno geo-histórico..., pp. 57-58.

25 AHN, NOBLEZA, Frías, Leg. 1305. 
Plasencia", de origen portugués a quien donó la aldea de Jaraicejo ${ }^{26}$. A Benito Pérez, "el ballestero", participante destacado en el cerco de Sevilla, hizo merced del despoblado de Ferruz, donde años después sabemos que había además de una dehesa para criar ganado unas treinta yugadas de tierra de labor, y a Domingo Velasco otorgó el lugar de la Peraleda27

Las concesiones territoriales ${ }^{28}$ que acabamos de señalar tienen unos rasgos comunes. En primer lugar todas están localizadas en el Campo de Arañuelo, la mayor sexmería de las que poseía el término pero la menos poblada hasta el punto que en 1254 sólo la aldea de Deleitosa, situada en el sureste del término de Plasencia, y Mirabel, en el extremo occidental de término de Plasencia, poseía parroquia ${ }^{29}$. En segundo lugar hay que señalar que los beneficiarios de las mercedes son caballeros al servicio de Alfonso X. Don Durán es el primer alcalde del rey en el concejo de Plasencia que tengo documentado, con una amplia actividad en otras zonas del reino. Por otra parte, Gonzalo Godínez y Domingo Velasco son escribanos reales ${ }^{30}$ De Benito Pérez sólo sabemos que es un miembro de la oligarquía de la ciudad pero, en todo caso, estamos ante un grupo de caballeros placentinos,

26 A este caballero se le cita algunas veces con el nombre de don Godino. J. BENAVIDES CHECA: Prelados Placentinos..., p. 351 M. GONZÁLEZ JIMÉNEZ: "Realengo y señorío: la intervención regia en los concejos a través de la creación de nuevos señoríos (1270-1295)" Estratto da Studia Gratiana, Vol. XXVIII, pp. 376 y ss. Hay bastantes noticias sobre este caballero así como sobre su hijo Alfonso Godínez en la obra de M. GAIBROIS DE BALLESTEROS: Sancho IV de Castilla. Madrid, 1928.

27 La noticia de la participación en la conquista de Sevilla la da D. SANCHEZ LORO: Historias Placentinas Inéditas... Vol. B, p. 79, nota 9 infra, pero en el Repartimiento de Sevilla, no he logrado identificarlo. Estudio y Edición de J. GONZÁLEZ, Sevilla, 1998. La carta de merced a Benito Pérez tampoco lo he podido hallar pero en otro documento conservado en el ACPL, Leg. 94-9b, fols. 12r.-13r. aparece dicho caballero como propietario de Ferruz. Sobre donación de Ferruz y la Peraleda, SANCHEZ LORO: Historias Placentinas Inéditas..., Vol. B., pp. 40 y 55.

28 Quiero advertir desde un principio, que excepto el caso de la concesión a Don Durán, los documentos originales de todas estas mercedes de Alfonso X no han llegado a mi poder sino que conozco los hechos a través de los datos suministrados por Domingo SÁNCHEZ LORO y J. BENAVIDES CHECA, con lo cual no puedo estar completamente segura si estamos ante la donación de señoríos plenos o son simples señoríos territoriales. De las noticias suministradas por ambos eruditos da la impresión de que son lo segundo y en ese sentido las he tomado.

29 V. PAREDES GUILLEN: Los Zúñigas, señores de Plasencia..., p. 65.

30 G. LORA SERRANO: El primer gobierno municipal... 
componentes algunos de su concejo, que como señala el profesor González Jiménez dominaban desde hacía tiempo la vida política de las ciudades y villas $^{31}$. Y la política de intervención regia en los concejos, iniciada por Alfonso X en Plasencia con la imposición a la ciudad en 1261 del Fuero Real $^{32}$, necesitaba del apoyo de dichos caballeros a quienes el rey Sabio convirtió en un instrumento fundamental de su política legislativa y fiscal ${ }^{33}$. Las mercedes que acabo de comentar y los privilegios de carácter más general que Alfonso X otorga a los caballeros y al concejo de Plasencia hemos de insertarlos pues en este contexto ${ }^{34}$. Y una última cuestión que quiero señalar es que estos minúsculos señoríos territoriales -a excepción de las tierras concedidas a Don Durán- permanecieron poco tiempo en manos de sus propietarios pues por diversas circunstancias, según ya veremos, cambiaron de manos.

B.-La consolidación del régimen señorial en la tierra placentina: los reinados de Sancho IV y Fernando IV.

El proceso señorializador se continuó a buen ritmo en esta época, aunque es bastante difícil de estudiar pues asistimos a un continuo trasvase de tierras y señoríos de unas manos a otras, de manera que hasta bien entrado el siglo XIV la titularidad de los señoríos cambia sin cesar. El Campo de Arañuelo sigue siendo el distrito rural donde se producen las mayores enajenaciones de tierras y vasallos. Sancho IV, en diciembre de 1284, otorgó a su escribano Gonzalo Godínez y a su mujer doña Sol el lugar de Jaraicejo. En la carta de merced no se hace ninguna referencia a la anterior concesión de Alfonso X por lo que el profesor M. González Jiménez cree que pudo deberse al hecho de que Gonzalo Godínez durante la guerra civil hubiera seguido el bando sanchista y como castigo fue desposeído de Jaraicejo ${ }^{35}$. Pero los

31 Alfonso X y las oligarquías urbanas de caballeros. Glossae, N. 5-6 (1993-1994). Instituto de Derecho Común. Universidad de Murcia, p. 202.

32 A. BARRERO, M.L. AlONSO: Textos de derecho local en la Edad Media. Catálogo de Fueros y Costumbres municipales. Madrid, 1988, p. 355.

33 M. GONZÁLEZ JIMÉNEZ: Alfonso X y las oligarquías urbanas..., p. 212.

34 G. LORA SERRANO: El primer gobierno municipal...

35 Realengo y señorío. La intervención regia..., p. 377. La merced de Sancho IV en J. BENAVIDES CHECA: Prelados Placentinos..., doct. I, pp. 352-353. 
Godínez retuvieron durante poco tiempo Jaraicejo en su poder puesto que en 1288 lo vendieron a Pedro Sánchez de la Cámara. Las razones de la venta pueden deducirse de la lectura de la carta de poder donde doña Mayor, dama zamorana viuda del hijo y sucesor de Gonzalo Godínez, facultaba a otro de sus hijos llamado Alfonso Godínez, uno de los privados Sancho IV cuya intervención en los más diversos asuntos y momentos del reinado fue constante, para que vendiera todas las posesiones que tenía en Plasencia y su término. Por ello se puede pensar que los miembros de esta familia, sin apenas vinculación con Plasencia, decidieron deshacerse unas propiedades bastante lejanas de Zamora, sobre las cuales quizás tenían escaso interés ${ }^{36}$.

El comprador de Jaraicejo, por el contrario, sí que podría estar interesado en adquirir la pequeña aldea puesto que Pedro Sánchez, a pesar de ser un caballero al servicio de Sancho IV, con una constante intervención en los asuntos del reino, sí que estaba arraigado en la vida de Plasencia. En efecto, este personaje había casado con doña Sol, hija de Gonzalo Pérez de Plasencia, otro importante caballero de Plasencia con propiedades lindantes con la aldea de Jaraicejo, y sin más descendientes que dos hijas que presumiblemente las heredarían ${ }^{37}$. Por eso la carta de Sancho IV, emitida en Haro el 31 de julio de 1288, "ordenando" a su escribano de Cámara que comprara Jaraicejo no podía ser más oportuna. En la misma, el monarca delimitó de nuevo los términos del señorío, algo distintos que los que otorgó a Gonzalo Godínez, y además concedió una serie de privilegios a los pobladores, todos vasallos, del flamante señor de Jaraicejo ${ }^{38}$. El mismo día se

36 Carta de poder en Ibídem, dcto. III, p. 355. Gonzalo Godínez y su mujer doña Sol tuvieron un hijo llamado como su padre que a su vez casó con doña Mayor. De este matrimonio nacieron dos varones. El mayor, también llamado Gonzalo Godínez murió sin sucesión y fue su hermano Alfonso, casado con Inés de Limógines, ama de leche del futuro Alfonso XI, quien por deseo de su madre vendió Jaraicejo. Datos genealógicos obtenidos en documento del ACPL, Leg. 94-1. Sobre Alfonso Godínez: M. GAIBROIS: Sancho IV de Castilla...

37 Gonzalo Pérez de Plasencia tuvo dos hijas, doña Jimena, casada con Alfonso Durán, alcalde del rey en Plasencia, de quienes descienden los señores de Almaraz y la citada doña Sol.

38 En la misma, además de otorgar privilegios a los pobladores ordena que el concejo de Plasencia, nin cogedores, nin sobrecogedores, nin arrendadores, nin pesquisidores, nin aportellados nin otros omes ningunos non sea osados de pasar contra ninguna destas cosas así en lo de los pechos como en lo de los términos. ACPL, Leg. 94-1, fols. 3rv. 
formalizó la compra de la aldea por precio de 10.000 mrs. y a comienzos del mes de diciembre, Sancho IV volvía a conceder amplias mercedes a los pobladores: no pechar portazgo, peaje y roda en los lugares y puertos del reino, salvo Toledo, Sevilla y Murcia, y ciertos privilegios judiciales como no ser los vecinos apresados salvo por deuda ${ }^{39}$, privilegios que se sumaron a los dados por el rey en el mes de agosto del año siguiente. Estudiados en otro lugar, aquí me interesa señalar que de su lectura se deduce cómo "la ganadería se perfilaba como la principal actividad económica de la aldea" 40 .

Pedro Sánchez de la Cámara inició a partir de entonces una política de adquisiciones de los territorios y heredades cercanas que le llevaron a formar un compacto señorío en los territorios bañados por el río Almonte: en octubre de 1290 mediante un trueque realizado con el monasterio de San Marcos de Plasencia se hizo con todos los bienes que el cenobio poseía en Ferruz, que eran los que Benito Pérez el ballestero, padre de María Domingo, monja profesa del convento, había recibido de Alfonso X y que en 1289 Sancho IV había concedido al monasterio para que a cambio las religiosas rogasen a Dios por su vida así como por el alma de Alfonso X. Parte de los mismos lindaban también con el señorío de Jaraicejo y estaban constituidos por una serie de heredades de pan, casas y una dehesa. A cambio el monasterio se quedaba con un palacio y una dehesa que poseía en la más lejana aldea de S. Pedro de Carcaboso, sita junto al Jerte, fuera ya del término de Plasencia ${ }^{41}$. A este conjunto de propiedades Pedro Sánchez añadió bienes diversos que le correspondieron de su mujer, la citada doña Sol, que debían ser cuantiosos puesto que él mismo declaró que quedó muy heredado ${ }^{42}$, más el pasaje de Albalat, en el río Tajo, y ciertos cañales adquiridos a Martín de Losa por compra. De la misma manera obtuvo de Teresa Sánchez, hija de Ibáñez Morejón y de doña Juana, ama de Sancho IV, el lugar de Almaraz, lindante con Jaraicejo, que la vendedora disfrutaba porque le había sido donado por

39 Carta de venta en J. BENAVIDES CHECA: Prelados Placentinos..., dcto. IV, pp. 356-357. Privilegios a los vecinos de Jaraicejo concedidos en Burgos a 6 de diciembre de 1288, en ACPL, Leg. 94-1, fols. 3v.-4r.

40 M. GONZÁLEZ JIMÉNEZ: Realengo y señorío..., p. 379.

41 Donación de Sancho IV en ACPL, Leg. 94-9b, fols. 12r.-13r. Carta de trueque en Ibídem, Leg.98-8b, fols. 10v.-11v.

42 Tan gráfica expresión se encuentra en Ibídem, Leg. 94-8, fols. 2r.-5r. 
dicho monarca ${ }^{43}$. El señorío que Pedro Sánchez de la Cámara logró formar al sur de la Tierra de Plasencia se completaba con otros bienes sitos en el término de Medellín. Eran la dehesa de Castil Rubio y el despoblado de Miajadas, obtenidos ambos por ciertos cambios que hizo con el concejo de Medellín y el rey. Al concejo entregó su dehesa del Encinar, mientras que a Sancho IV dio el lugar de Bustiello. En ambos casos, el rey mandó a su oficial que puesto que ambas propiedades están en tierras de golfines que lo labre y lo pueble en aquella guisa que él mejor pudiere 44 .

El 11 de julio de 1294, fallecida doña Sol, Pedro Sánchez de la Cámara dispuso su testamento. En el mismo una parte sustancial de sus bienes fueron donados al obispado de Plasencia. De esta manera, Jaraicejo "con las casas e la torre que yo y a e con su cortyjo e con los vasallos que son agora y poblados", y con las demás bienes que había en el señorío, las propiedades de Ferruz y las localizadas en el término de Medellín, pasaron a formar parte del dominio de dicho obispado45. En 1293 Sancho IV aprobó la donación. Las palabras que el obispo de Plasencia dirigió al rey cuando le pidió que confirmase a los vecinos de Jaraicejo todos los privilegios que tenían de los años anteriores dan a entender que aquéllos no recibieron de buen grado a su nuevo señor 46 .

Pero no fue sólo Pedro Sánchez de la Cámara quien recibió de Sancho IV villas y aldeas del término de Plasencia. En el mes de enero de 1290 el monarca por ruego de la reina doña María, mi muger, concedió a Ferrán Pérez de Plasencia, vasallo del infante don Fernando, que en el lugar de Belvís, muy cercano a Almaraz, tuviera 30 vasallos. La carta de merced le entregaba a Ferrán Pérez todos los pechos debidos al rey, menos la moneda

43 La relación de estas adquisiciones está en un documento emitido por el concejo de Plasencia donde ratifica a Pedro Sánchez de la Cámara la posesión de sus propiedades en el término de Plasencia J. BENAVIDES CHECA: Prelados Placentinos..., deto. XIII, pp. 370371. M. GONZÁLEZ JIMÉNEZ: Realengo y señorío. La intervención regia en los concejos..., p. 380.

44 D. SANCHEZ LORO: Historias Placentinas Inéditas...Vol. B, pp. 80-81.

45 ACPL, Leg. 94-8, fols. 2r.-5r. Confirmación de la donación de Fernando IV en Ibídem, Leg. 94-7.

46 “... porque las cartas destas libertades y destas franquezas, que los de Xahariçejo habían hablan en nombre de Pedro Sánchez, que agora dicen que el lugar es suyo, que les pasan contra ello y que se lo no guardan, ni quieren hacer por las cartas ninguna cosa". Ibídem, Leg. 94-1, fols. 1r.-2r. 
forera, le otorgaba la justicia del lugar y por último le señalaba una dehesa para uso exclusivo del titular del señorío y de sus vasallos ${ }^{47}$. Con esta merced otro linaje placentino, el de la Casa del Bote, se asentaba en el Campo de Arañuelo sobre el cual ejercieron un notable dominio a lo largo de toda la Edad Media ${ }^{48}$.

La familia de Don Durán, que fue el tronco del linaje de los Almaraz, también consolidó su presencia en el Arañuelo: quizás por esas mismas fechas o incluso antes Sancho IV entregó a su alcalde Alfonso Durán de Plasencia, hijo de don Durán, la aldea de Deleitosa con todos sus términos y pertenencias. El hecho es conocido por una carta de Fernando IV donde confirma la merced anterior realizada por su padre ${ }^{49}$. Deleitosa se encontraba así mismo muy cerca de Almaraz donde ya poseía las yugadas donadas en 1256 por Alfonso X. Por otra parte la boda del alcalde placentino con doña Jimena, otra hija de Gonzalo Pérez de Plasencia, le había proporcionó más bienes en el mismo espacio territorial ${ }^{50}$. Los dominios del alcalde placentino en el Arañuelo se completaron con una nueva merced regia, efectuada en fecha incierta pero en todo caso anterior a 1298, que le convirtieron en flamante propietario de unos bienes cuya consideración no puedo precisar en la aldea de Torrejón el Rubio ${ }^{51}$.

Las últimas mercedes de época de Sancho IV que conozco fueron las otorgadas a Pedro Sánchez, del linaje de Trejo. Esta familia de oscura ascendencia, ya que los genealogistas no se ponen de acuerdo sobre la misma $^{52}$, debió llegar a Plasencia a fines del siglo XIII cuando aparecen las primeras noticias del mismo. Uno de sus miembros, Pedro Sánchez recibió del monarca Grimaldo, Monfragüe y Las Corchuelas, al sur del término de

47 AHN, NOBLEZA, Frías, Leg. 1249-16.

48 Ferrán Pérez de Plasencia era hijo de un criado del infante don Felipe llamado Julián Pérez, I señor del Bote. Ibídem, Leg. 1249-4.

49 Ibídem, Leg. 1327.

50 No se cuales son con exactitud pero hay noticias que hablan Gonzalo Pérez de Plasencia partió sus bienes entre sus dos hijas. J. BENAVIDES CHECA: Prelados Placentinos..., dcto. XV, pp. 373-375.

51 D. SÁNCHEZ LORO dice que en 1298 Alfonso Durán era señor de Torrejón el Rubio. Historias Placentinas Inéditas, Vol. B, pp. 188-189.

52 SALAZAR Y CASTRO en su Historia de la Casa de Lara... los hace descender de un merino mayor de Galicia llamado Ruy García de Trejo. 
Plasencia. En 1370 un sucesor de este caballero llamado Gonzalo Bermúdez de Trejo pidió a Enrique II que le confirmase la merced de su antecesor puesto que en un incendio se habían quemado los documentos que así lo acreditaban. A través de la confirmación del primer Trastámara sabemos que Sancho IV no sólo entregó a su vasallo aquéllas pequeñas aldeas y lugares sino que además le otorgó el privilegio de que en sus casas de Plasencia se pudiera refugiar cualquier persona que huyera, no pudiendo ser tomado preso por ningún oficial de justicia ${ }^{53}$.

En la época de Fernando IV la señorialización del término alcanzó a las sexmerías de la Vera y del Valle y Trasierra. Las primeras concesiones datan del año 1303. En el mes de febrero otorgó al placentino Nuño Pérez de Monroy, hermano de Fernán Pérez, los señoríos de Jarandilla y Valverde con los lugares de Madrigal, Talavera y Viandar ${ }^{54}$ y semanas después hizo merced a Fernán Gómez, su notario en el reino de Toledo y a Diego García, mayordomo de su casa, de la aldea de Albalá, en el Campo de Arañuelo, junto a la ribera del Tajo ${ }^{55}$. En noviembre de 1304 entregó a su alcalde Durán Sánchez de Plasencia, la aldea de Deleitosa, a cambio de la casa de Almaraz, que se la cedió a su tío, el inquieto infante don Juan ${ }^{56}$. Este trueque, que puede despejar las dudas acerca de la creación del primer señorío en tierras de Plasencia ${ }^{57}$, plantea sin embargo varios interrogantes. $Y$ el primero de ellos es sobre la filiación de Durán Sánchez, de la que no poseo ninguna información aunque su descendencia en la ciudad sí que está perfectamente localizada ${ }^{58}$. La primera referencia que tengo del mismo es de 1293, año en que aparece

\section{D. SÁNCHEZ LORO: Historias Placentinas Inéditas, Vol. B., pp. 245-251.}

54 Concesión de Jarandilla y Valverde en AHN, NOBLEZA, Frías, Leg. 1362-1. Sobre este personaje Vid. la nota n. 68 de este trabajo.

55 El 10 de marzo de 1303. A. BENAVIDES: Memorias del rey D. Fernando IV de Castilla. T. II, Madrid, 1860, Dcto. CCXXX, pp. 346-348.

56 AHN, NOBLEZA, Frías, Leg. 1327 Documento inserto en una copia de 6 de julio de 1544 .

57 Vid. páginas anteriores y notas n. 22 y 23.

58 Durán Sánchez casó con doña Susana y fruto de ese matrimonio fueron tres vástagos. Doña Juana, Sancho Durán y Pedro Sánchez. Este último caballero junto a otros parientes suyos se vieron envueltos en unos tumultuosos hechos que acabaron con la muerte de los alcaldes de Plasencia. AHN, NOBLEZA, Frías, Leg. 1249-4 bis. 
como delegado regio en cuestiones fiscales ${ }^{59}$. Nada más se sabe de este personaje hasta que en 1304 recibió Deleitosa. Otra cuestión a determinar es la forma en la que la casa de Almaraz llegó a su poder. Su anterior propietario, Pedro Sánchez de la Cámara, no la nombra en su testamento, por lo que es probable que ya no se contara entre sus bienes y de hecho existen noticias acerca de un privilegio de Fernando IV emitido en octubre de 1299 donde se confirma (no se dice a quien) la compra del lugar de Almaraz ${ }^{60}$. Por tanto, todo induce a pensar que quizás Durán Sánchez la adquirió, ya que el alcalde placentino había iniciado una política de compras de bienes y heredades diversas que le habían convertido en un notable propietario en la cercana aldea de Albalá. Así mismo, las propiedades que Pedro Sánchez había disfrutado en Medellín -y posteriormente legado al obispado de Plasencia en su testamento- también habían ido a parar a sus manos ${ }^{61}$. La última cuestión que en este tema se plantea es por qué Deleitosa había vuelto de nuevo al realengo puesto que Fernando IV dispuso de la misma para entregarla a su alcalde. Las fuentes de la época no dicen nada al respecto ${ }^{62}$ y lo único cierto es que tanto Almaraz como Deleitosa no estuvieron mucho tiempo ni en poder de Durán Sánchez ni en el del Infante puesto que en 1343 Juan Alfonso de Almaraz, hijo de Alfonso Durán, instituyó mayorazgo en favor de su hijo Blasco Gómez donde se incluían estas propiedades ${ }^{63}$. La anarquía reinante en Castilla y el afán de la monarquía para lograr el apoyo de las ciudades y de personas influyentes en las mismas -que fueran capaces de hacer frente a las ambiciones de los grandes personajes del reinado- pueden ayudar a explicar

59 Concretamente en las cuentas de Sancho IV del obispado de Burgos en las que el monarca manda a Alvar Pérez, para su casamiento 4.000 mrs. librados en Durán Sánchez y en don Samuel de Bilforado. M. GAIBROIS DE BALLESTEROS: Historia del reinado de Sancho IV, I, XXVI.

60 J. BENAVIDES CHECA: Prelados Placentinos..., p. 313.

61 Así se señala en una carta de Fernando IV al maestre de Calatrava el 5 de mayo de 1309. A. BENAVIDES: Historia del reinado de..., dcto.. CDLXVII, pp. 680-681.

62 Domingo Sánchez Loro en sus Historias Placentinas Inéditas, Vol. B, pp. 188-190 declara que 1292 era señor de Deleitosa Fernán Pérez del Bote y que Alfonso Fernández del Bote hizo mayorazgo de esta villa en 1329. La primera noticia no la he podido constatar documentalmente, pero respecto a la segunda se puede señalar que si bien es cierto que Alfonso Fernández del Bote hizo testamento donde instituyó un mayorazgo en favor de su hijo Pedro en el mismo no se incluye Deleitosa. AHN, NOBLEZA, Frías, Leg. 1249-4.

63 Ibídem, Leg. 1328-2. 
este continuo trasvase de señoríos de unos propietarios a otros. En este complicado panorama político tenemos que insertar la nueva amputación de tierras de su término que en 1305 sufrió el concejo placentino, porque Garganta la Olla, Torremenga y Pasarón fueron a formar parte del extenso señorío otorgado en la sentencia arbitral de Torrellas al infante don Alfonso de la $\mathrm{Cerda}^{64}$.

La última merced que conocemos correspondiente a la época que estudiamos es la que Fernando IV hizo a Fernán Pérez de Plasencia, conocido también con el nombre de Ferrán Pérez de Monroy al que concedió que su lugar de Monroy, en el Arañuelo, fuese poblado con 100 vasallos. Así mismo le otorgó la jurisdicción sobre el mismo reservándose el rey sólo la percepción de la moneda forera ${ }^{65}$. El caballero citado era miembro de uno de los linajes más antiguos de Plasencia, el de los Monroy, llegado a la ciudad en su época fundacional ${ }^{66}$. A comienzos del siglo XIV ocupaba un oficio en la Corte -era copero mayor de la reina doña María- y participaba en primera línea en la vida del concejo de Plasencia. Su actividad en el seno del mismo se detecta desde 1307, cuando es procurador del Plasencia en las Cortes de Valladolid ${ }^{67}$. Con

64 GONZÁLEZ MÍNGUEZ, C.: Fernando IV de Castilla (1295-1312). La Guerra civil y el predominio de la nobleza Álava, 1976, p. 185. AMADOR DE LOS RÍOS, R.: Huelva. El Albir. Barcelona, 1983, p. 601.

65 AHN, NOBLEZA, Frías, Leg. 1324-9.

66 Sobre la ascendencia de los Monroy los cronistas no se ponen de acuerdo. E. DE TAPIA en sus Crónicas Trujillanas del siglo XVI, p. 285 dice que descienden del conde don Ramón, poblador de Salamanca. Ed. de M. MUÑOZ DE S. PEDRO. Por su parte el cronista de este linaje, A. MALDONADO afirma que fueron los herederos de un miembro de la familia real de Francia que estuvo junto al rey Pelayo en Covadonga. Hechos del Maestre de Alcántara don Alonso de Monroy. Revista de Occidente, 1935, p. 7. V. PAREDES siguiendo a Pellicer los hace sucesores de un colono de Plasencia, que no cita de donde procedía, llamado Pedro Fernández Vigil. Sus bisnietos fueron Nuño y Fernán Pérez de Monroy. Señorío de Monroy "Revista de Extremadura", 1905, p. 550. Para fray Alonso FERNÁNDEZ fue un servidor de Fernando III llamado Pedro Fernández de Monroy el abuelo de este caballero. Historia y Anales de la Ciudad y Obispado..., p. 76.

67 Fray ALONSO FERNÁNDEZ declara que en estas Cortes solicitó que la guarda de los puertos de la ciudad, que compartía con Alonso Fernández del Bote desde época de Alfonso X le fuera confirmada. Historia y Anales de la Ciudad..., p. 92. Pero en el cuaderno de estas Cortes otorgado a Plasencia su nombre no aparece aunque sí en el de las Cortes de Burgos de 1315. AMPL. Leg. 1-4 y 4 bis y 6 y 6 bis. 
esta merced Ferrán Pérez de Monroy se perfilaba como uno de los principales caballeros no sólo de Plasencia sino de la Alta Extremadura y su linaje se convertía probablemente en el principal de la Plasencia de su época y no sólo por el rango que en la Corte había adquirido Ferrán sino sobre todo por el que poseía su hermano Nuño Pérez de Monroy, abad de Santander, escribano y canciller de la reina doña María y servidor de Sancho IV, Fernando IV y Alfonso XI, en cuya minoría tuvo un importante papel oponiéndose a las ambiciones del infante don Juan así como a don Juan Núñez de Lara ${ }^{68}$. La posición económica y social de Ferran Pérez de Monroy se incrementó de forma notable cuando su hermano el abad testó en 1326 pues entre los bienes que le legó estaba el señorío de Valverde ${ }^{69}$.

En conclusión, en la primera época del siglo XIV la extensión del régimen señorial por las tierras del término de Plasencia era ya notable especialmente en los territorios comprendidos entre el Tajo y el Almonte. Las concesiones de estos señoríos tienen algunos rasgos comunes con los otorgados en época de Alfonso X. Por ejemplo, las mercedes son realizadas para que el nuevo propietario impulsara la repoblación del lugar donde la presencia de golfines la dificultaba: “...el lugar de Xaharicejo es en fuert logar e muy çerca de la Xara e en logar de grand peligro de golfines e mandamos a Pero Sánchez de la Cámara que lo poblase porque es seruiçio de Dios e nuestro e guarda de la tierra."70. Incluso hay casos en los que el monarca ordena construir fortalezas que apoyen la defensa de las tierras y consoliden la labor repobladora. Es lo que pide Sancho IV a su vasallo Ferrán Pérez cuando le concede que en la cabeza Belvís pueda tener 30 vasallos ${ }^{71}$. Mas hay notables diferencias con las estudiadas de época anterior. Para empezar es a partir de la época de Sancho IV cuando tenemos las primeras

68 Fray Alonso Fernández: Historia y Anales de la Ciudad y Obispado..., pp. 94-95. Don Nuño había nacido en 1260 en Plasencia y había participado junto a Sancho IV en varias guerras. Fue nombrado escribano del infante don Fernando cuando se organizó la Casa del Príncipe en 1285. En las cuentas del monarca aparece como "Don Nuño Pérez, escribano de la Reina". Todos los datos en la obra de M. GAIBROIS DE BALLESTEROS: Sancho IV de Castilla... GONZÁLEZ MÍNGUEZ, C.: Fernando IV de Castilla (1295-1312)..., p. 30, 306 y 310. Edificó el hospital de S. Marcos de Plasencia.

69 AHN, NOBLEZA, Frías, Leg. 579-10 (signatura antigua aún no cambiada).

70ACPL, Leg.94-1, fols 1r-2r. En el mismo sentido se expresa Fernando IV en la concesión de Monroy. AHN, NOBLEZA, Frías, Leg.1324-9.

71 Ibidem, 1249-16. 
noticias que nos indican que se concede jurisdicción sobre lugares en los que los beneficiarios de la merced ya tenían un dominio solariego ${ }^{72}$. Y no fue hasta el reinado de Fernando IV cuando aparecieron los primeros señoríos cuyos beneficiarios recibieron no sólo unas tierras para su disfrute sino también la jurisdicción sobre las mismas "e con todos los derechos e pertenençias e pechos que yo hi he; asi serviçios, como pedidos, é emprestidos e martiniegas... como todos los otros pechos que acaescan daqui adelante, que me hobieren a dar los de la tierra"73. Por último quisiera señalar que los beneficiarios de las mercedes son, salvo casos contados, personajes de la vida de Plasencia, algunos con cargos en la Corte, tal y como hemos visto, y otros en el concejo de Plasencia. En todo caso son caballeros muy implicados en la vida de la ciudad, cabezas o miembros de los linajes que vivieron a lo largo de los siglos bajomedievales en Plasencia y su Tierra por lo que las mercedes que recibieron fueron incluidas en los mayorazgos que a su muerte instituyeron y por eso son los bienes nucleales de ciertos estados señoriales del siglo $\mathrm{XV}^{74}$.

$$
\text { o-O-O }
$$

Y me gustaría terminar este pequeño trabajo con una reflexión acerca de la posición que el concejo de Plasencia tomó ante el proceso de señorialización de las tierras de su alfoz, una situación que lesionaba seriamente sus intereses por la pérdida de tierras, vasallos y determinados beneficios obtenidos del dominio jurisdiccional que le correspondía. Las

72 Como en el caso de la cabeza de Belvís que acabo de citar. También en el de Jaraicejo: "Y mandamos que los que son alli agora poblados y vinieren a poblar de aquí adelante, que sean sus vasallos".J. BENAVIDES CHECA: Prelados Placentinos..., Dcto.. I, pp. 352-353. Otro ejemplo en AHN, NOBLEZA, Frías, Leg. 1249-16.

73 A. BENAVIDES: Memorias del rey Don Fernando IV..., Dcto. CCXXX, pp. 346348. AHN, NOBLEZA, Frías, Leg.1362-1. Ibídem, Leg. 1327.

74 Vid, por ejemplo el caso de Belvís, Almaraz, Valverde y Deleitosa o Jaraicejo que continuó en manos del obispo de Plasencia. A. FRANCO SILVA, J.L. del PINO GARCÍA: El señorio de los Monroy... Por el contrario, hay casos en los que bien por falta de descendencia o por otras razones las villas señorializadas volvieron a reintegrarse en la Corona. Fue el caso de Jarandilla, propiedad del clérigo Nuño Pérez que en 1360 fue comprada por el concejo de Plasencia a Pedro I, aunque posteriormente Enrique II se la entregó junto a Tornavacas a García Álvarez de Toledo. A. FRANCO SILVA, J.L. del PINO GARCIA: El Campo de Arañuelo en el siglo $X V$..., p. 44. 
informaciones que tenemos son bastante contradictorias: dos testimonios de época de Sancho IV nos indican que la actitud del concejo ante dicho proceso fue si no favorable al menos conforme, como lo demuestra el hecho de que fuera el mismo cabildo de Plasencia el que "entregase" en febrero de 1289 el señorío de Jaraicejo a Pedro Sánchez de la Cámara, después que este caballero se lo hubiera en realidad comprado a los Godínez y que también "confirmase" a Alfonso Durán la merced que el mismo monarca le había hecho de Deleitosa ${ }^{75}$, actos que se han entendido "como una formalidad necesaria para dar carácter de legalidad a lo que a primera vista pudiera considerarse como una usurpación pura y dura" 76 , pero que resultan un tanto insólitos.

Pero esta actitud no siempre debió mantenerse puesto que sabemos que en 1292 Sancho IV ordenaba al concejo placentino que no impidiera al mismo Alfonso Durán disfrutar de ciertos bienes en el Arañuelo, y pocos años después Fernando IV prometía a Durán Sánchez “de vos fazer sanna e defender la aldea sobredicha de dizen Deleytosa también del conçejo de Plasençia como de cada uno del conçeio e de otros e ni qualer quier que vos la aldea embarguen e demandar quisieren por qual quier razón. E mandamos a todos los conçejos del obispado de Plasençia que vos defiendan"77, lo que nos indica si no una abierta oposición, al menos una clara discrepancia del concejo con la actitud real. En todo caso lo único que puedo afirmar es que no tengo ninguna evidencia directa de tal oposición, como tampoco poseo manifestaciones de movimientos antiseñoriales, sino sólo las promesas de amparo de los monarcas o sus cartas ordenando que se cumpliesen sus decisiones. Fuese de una manera $u$ otra no podemos olvidar que aunque en un principio, la señorialización de las tierras del término de Plasencia fuera, ante todo, contraria a los intereses de su concejo, hay que tener muy en cuenta que en gran parte de las ocasiones las mercedes han recaído en miembros de la oligarquía de caballeros de Plasencia muy ligados a su órgano de gobierno municipal, con lo cual está clara la posición que aquél toma ante el problema suscitado. Por otra parte, la despoblación de estos territorios pudo influir también para que el concejo de la villa no opusiera una serie resistencia a este fenómeno señorializador.

75 J. BENAVIDES CHECA: Prelados Placentinos..., deto. VIII, pp. 362-363. AHN, NOBLEZA, Frías, Leg. 1327.

76 M. GONZÁLEZ JIMÉNEZ: Realengo y señorío: la intervención regia..., p. 378.

77 AHN, NOBLEZA, Frías, Leg. 1305. Ibídem, Leg. 1327. 
Y un último apunte: si bien es cierto que Plasencia aceptó de mejor o menor grado que los monarcas hicieran las concesiones que en las páginas anteriores hemos comentado, al amparo del derecho eminente de soberanía sobre las tierras integradas en un término concejil, sabemos que también luchó denodadamente por las invasiones que de sus términos efectuaron tanto los vecinos concejos de Béjar y Avila, como la orden del Temple, el concejo de la Mesta y sobre todo los placentinos propietarios de tierras. De esta manera Plasencia inicia desde fines del siglo XIII una lucha secular por la reintegración de las tierras concejiles que a comienzos del siglo XVI aún estaba sin resolver ${ }^{78}$.

78 Los conflictos con Béjar en AMB, Colección Diplomática, Leg. 1-2. Los mantenidos con Avila en J. GONZÁLEZ: Reinado y Diplomas..., Vol. III, dcto. 833, p. 418. Con la orden del Temple en D. SÁNCHEZ LORO: Historias Placentinas Inéditas..., Vol. B., pp. 88-92 y con la Mesta en ACPL, Leg. 29-6. Ejemplos de pleitos con los placentinos en AHN, NOBLEZA, Frías, Leg. 1305. 